\title{
The weather a week ahead
}

\section{Ernest Knighting describes the establishment of the European Centre for Medium Range Weather Forecasts}

$\mathrm{R}^{\mathrm{E}}$ LIABLE weather forecasts for a week or so ahead would be of great economic value; almost every industry, including agriculture, transport, building, shipping, fuel and power, would benefit in the planning of operations and, of course, the general public would be better able to plan outdoor activities. And if, as has been estimated, the benefit to Europe would be more than $£ 100$ million a year at 1970 values, it is well worth setting up an organisation to conduct research into problems associated with medium range forecasting, and eventually to provide operational forecasts.

The resources of skilled manpower and equipment required for such a task, however, exceed those normally available at national level. This makes an international co-operative effort necessary, and in October 1973 sixteen European nations signed a Convention establishing the European Centre for Medium Range Weather Forecasts. By November of last year a sufficient number of nations had ratified the Convention for the Centre to come into being. Belgium, Denmark, West Germany, Spain, France, Ireland, Yugoslavia, the Netherlands, Austria, Portugal, Switzerland, Finland, Sweden, Turkey and the UK have ratified, while both Greece and Italy are expected to ratify shortly.

The Centre's headquarters (to be erected by the UK Government) will be at Shinfield Park, Reading, England; temporary accommodation has meanwhile been provided at Bracknell. The Centre will have a staff of about 140 , including about 70 graduates, mostly in the research and operations department. The present staff, numbering about 40 , reffects the international character of the Centre, with nine member nations being represented. In addition there will be opportunities for visiting scientists to work at the Centre.

The Director, the well-known Danish meteorologist, Professor Aksel WiinNielsen, was formerly Head of the Department of Atmospheric and Oceanic Sciences at the University of Michigan; he, together with a small planning staff, laid the foundations of the Centre's development so that at its official birth it was already welladvanced in its scientific and operational planning. When the Centre is fully operational it is expected to have a yearly budget of about $£ 6$ million; the cost will be met by the member nations, contributions being scaled according to the gross national product of each nation.

The central premise of the develop- ment of these operational forecasts is that the atmosphere may be regarded as a compressible fluid, its behaviour being described by the Navier--Stokes equation and the thermodynamic equations concerned with sources, sinks and the transfers of energy. Considerable progress has been made in the last two decades in using these equations for two distinct objectives. The first is for short-range weather forecasts for a day or two ahead, and it is now common for national services, especially those in extra-tropical latitudes, to base their short-range forecasts on the numerical integration of the equations. The problem is the prediction with considerable accuracy of the motion and development of weather-bearing systems, which have a lifetime of a week or so; it requires a fairly precise knowledge of the state of the atmosphere at the instant from which the forecast proceeds, while some slow acting physical processes may be neglected.

The second objective is to determine why the atmosphere has its general climatic structure and to throw light on climatic change. In this research the equations are integrated for perhaps a hundred days or more rather than for the one or two days of the short-range forecast. During this period many generations of weather-bearing systems undergo their life history and the emphasis is no longer on the initial detail but on the careful representation of the physical processes that are thought to be important for the atmospheric development over a long time, such as incoming and outgoing radiation, the transfer of energy at the earth's surface and so on.

Forecasting for up to ten days ahead presents a more difficult problem because both the initial details and the careful accounting for the physics have to be taken into consideration. The detail must be considered because the evolution of the atmospheric systems in existence initially has a considerable effect over the period; indeed, some of the systems may persist, although modified in form and position, for most or the whole of it. The changes caused by the slow acting physical processes can also be profound during the period; the effect of a change in sea surface temperature, for example, due perhaps to up-welling, can be remarkable. Over a few days the development of the weather bearing systems over Europe and the Atlantic can be affected by what is happening very far away, and forecasts for ten days ahead need to be global, taking

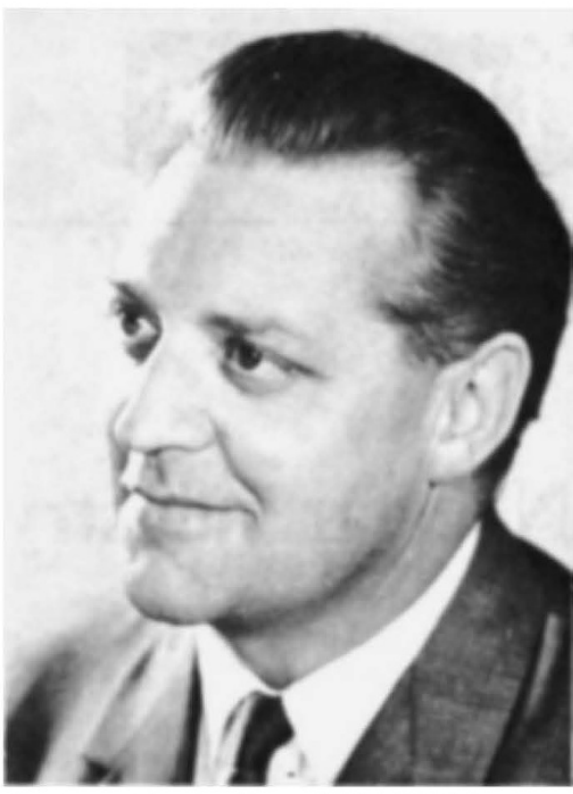

Professor Wiin-Nielsen, ECMRWF Director

into account the developments in the Southern Hemisphere, which are less well defined, as well as in the Northern Hemisphere.

The equations describing the evolution of atmospheric motions are highly non-linear and whether any useful analytic solutions will ever be obtained seems doubtful. Certainly the only known methods of solution are numerical, and the arithmetic burden is enormous : operational numerical forecasts for a couple of days ahead require the use of large-scale computing facilities with speeds of operation of about 10 million instructions per second; computations associated with operational forecasting up to ten days ahead call for facilities about five times as fast.

If the Centre is to achieve the difficult, perhaps impossible, target it has set itself-namely to be in a position to provide daily operational forecasts before the end of 1980 -there must be scientific research and development on three fronts. The first concerns the acquisition of the right daily data, its verification and reduction to a suitable form. This problem has become very complicated because a great number of meteorological data, especially those from satellites, are observed continuously and require special methods of assimilation if they are to be used in the forecasting process. The second concerns the important physical processes which often cannot be represented directly in the computations because the arithmetic has to be carried out for discrete grid points about $100 \mathrm{~km}$ apart. Atmospheric processes smaller in size than this can only be represented statistically in the computations. Many of the important energy transfers-those due to vertical instability and the development of cumulo- 
nimbus clouds, for example-are subgrid scale in size and their important contribution to the working of the atmosphere needs investigating. The third concerns the selection of the mathematical methods of integration, where there will be a delicate balance between accuracy and economy.

An additional complication is the problem of predictability which is currently exercising meteorologists. It is the problem of determining for how long ahead useful forecasts can be made. It is generally agreed that the limit is less than one month and more than five or six days, using current mathematical models and the meteorological observations presently available. Experimental determination of the limit by integration of the model equation is very difficult because a few integrations cannot give results representative of so variable a fluid as the atmosphere, while each integration predicting for, say, 14-20 days, is extremely costly. Experiments carried out up to date show that there is value in the forecasts up to ten days and this is confirmed by the few integrations carried out at the Centre. The Centre will cooperate as fully as it can in the First GARP Global Experiment, which is designed, among other objectives, to determine the limit of predictability.

With the aid of computer programmes for atmospheric models provided by the Geophysical Fluid Dynamics Laboratory of Princeton, the Department of Meteorology, UCLA, and the UK Meteorological Office, this research has already started. Ten days forecasts have already been made with these models, using both a CDC 6600 computer installed for the Centre's use by CDL in Bracknell and the UK Meteorological Office computer complex; their production is regarded as a familiarisation exercise.

A considerable effort must also be devoted to the selection and installation of suitable computing facilities; speeds of 50 million instructions per second are only just being developed and the selection of an integrated system capable of carrying out the data processing and the number-crunching on an operational basis will certainly present difficulties. Of course, the system must be available before 1980 since the Centre will need to develop its operational programmes on it.

Europe, through the member nations, has created the first scientific centre for the study and preparation of medium range weather forecasts. The international meteorological community has expressed great interest in this new venture with offers of help and cooperation. Already a cooperative agreement has been signed with the World Meteorological Organisation and the provision of computer programmes is one example of the help that has been made available. Nevertheless the Director and his staff face a difficult task in attempting to build up a new international scientific centre in a time of recession.

\section{Science vs. the public}

Colin Norman reports from Cambridge, Massachusetts, where attempts are being made to restrict recombinant $D N A$ research.

IN a move which establishes a virtually unprecedented degree of community control over an area of scientific research, the city council of Cambridge, Massachusetts, last week passed a resolution calling for a three-month moratorium on certain types of recombinant DNA research at Harvard and Massachusetts Institute of Technology. Though the moratorium will have little immediate impact, since experiments of the types outlawed by the council are not yet being conducted at either university, the council's actions could have broad and lasting implications.

While the moratorium is in effect, a special review board, also established by the council last week, will draw up recommendations to control recombinant DNA research in Cambridge. In addition the board has been given the astonishing task of reviewing all laboratory experiments in the city, to ensure that none of them poses a threat to public health.

The council's actions are the result of a bitter clash between groups of scientists, city officials and Cambridge residents over plans to conduct recombinant DNA research at Harvard and MIT. The dispute, which centres on the question of whether or not such experiments can be carried out safely, has been a bloody battle which has provided ample evidence of public distrust of scientists and which has further damaged the already abysmal relationships between the city and its two famous universities.

In a sense, the clash has also provided the first real test of public acceptability of federal safety guidelines governing recombinant DNA research issued last month by the National Institutes of Health (NIH) (see Nature, July 1). The guidelines were developed mostly by scentists, and have not previously been subjected to the intense public scrutiny now being lavished on them in Cambridge. Those who support the guidelines-and they include the vast majority of the scientific community--can take little comfort from the public debate in Cambridge. Moreover, many scientists are worried that similar clashes could break out elsewhere, a development which the Mayor of Cambridge has been doing his best to promote by trying to interest his fellow mayors in the issue.

The hostilities stem originally from a proposal, put forward two years ago by a group of scientists headed by Mark Ptashne, to convert some rooms on the fourth floor of the Harvard Biological Laboratories into a special safety facility. Designed primarily for experiments with the animal virus SV40-experiments which are frequently carried out in other institutions under much less stringent safety conditions - the facility became a major focus of controversy when the plans were modified to include space for some recombinant DNA work.
At present, Harvard researchers are restricted to experiments, judged by those who wrote the guidelines to entail little risk, which do not require special safety facilities. According to Matthew Meselson, Chairman of the Department of Biochemistry and Molecular Biology, about 30 people at Harvard are now working, at various levels, on such experiments. Construction of the safety laboratory - a moderate containment, or P3, facility under the NIH guidelines-would allow many other types of experiments to be undertaken at Harvard.

Opposition to the facility came first from scientists at Harvard. It took two forms. Some argued that although recombinant DNA research is an exciting and potentially revolutionary area of research which should be conducted at a major research institute like Harvard, the building housing the biological laboratories is unsuitable for a safety facility. It is old, infested with ants and cockroaches, and situated in a densely populated area. The second, more fundamental objection came from scientists who argued that recombinant DNA research is inherently so risky that virtually all such experiments should be confined initially to one or two specially equipped national facilities, or be outlawed entirely, until the hazards are better defined.

In spite of the intensity of the opposition construction of the facility has been approved in principle by a special biohazards committee, by Harvard's top-level committee on research policy, and by the Dean of Arts and Sciences. Final plans for the lab are now being drafted. 